\title{
The prevalence of oropharyngeal squamous cell carcinoma in patients admitted with symptoms of peritonsillar abscess or cellulitis: a retrospective multicentre study
}

\author{
Andrew Lau ${ }^{1}$, Kristijonas Milinis ${ }^{2}$, Mila Roode ${ }^{1}$, Stephen Williams ${ }^{3}$, Colette Cook ${ }^{4}$, \\ Hussein Walijee ${ }^{5}$, Matthew Zammit ${ }^{6}$, Richard Siau ${ }^{6}$, Hannah Emerson ${ }^{7}$, Rosie Wright ${ }^{7}$, \\ and Thomas Hampton ${ }^{8}$ \\ ${ }^{1}$ Aintree University Hospitals NHS Foundation Trust \\ ${ }^{2}$ Royal Liverpool and Broadgreen University Hospitals NHS Trust \\ ${ }^{3}$ Arrowe Park Hospital \\ ${ }^{4}$ Countess of Chester Hospital \\ ${ }^{5}$ Leighton Hospital \\ ${ }^{6}$ Royal Liverpool and Broadgreen Hospitals NHS Trust \\ ${ }^{7}$ Warrington Hospital \\ ${ }^{8}$ Mersey ENT Research Collaborative
}

April 14, 2021

\begin{abstract}
ABSTRACT Objectives Anecdotal evidence suggests that oropharyngeal squamous cell carcinoma (OPSCC) should be suspected in patients presenting with symptoms of peritonsillar abscess (PTA) or cellulitis (PTC). The aim of this study was to estimate the prevalence of OPSCC in patients presenting with symptoms of PTA/PTC. Method, Setting and Participants We retrospectively identified all adults with a coded diagnosis of PTA or PTC who presented between 2012-2016 inclusive, across six ENT units in - Records were compared to that of the centralised regional head and neck cancer database. The clinical records of a subset of patients were reviewed for the purposes of data validation. Results A total of 1975 patients with PTA/PTC were identified. Three patients were subsequently diagnosed with OPSCC. None of the three actually had an objective underlying diagnosis of PTA/PTC on the same side. The prevalence of OPSCC in patients admitted with symptoms of PTA/PTC was $0.15 \%$, or approximately 1:650 admissions. The records of 510 patients who presented over a one-year period (2016) were reviewed in even greater detail. There were 298 patients with PTA (59.4\%), 151 with PTC (29.1\%) and 61 had an alternative diagnosis (11.9\%). High risk features (age [?]40, tonsillar asymmetry or tonsillar lesion) were present in 106 patients (24\%). Urgent follow up was expedited for 77 patients (73\%). Conclusion This study estimates the risk of OPSCC in patients with peritonsillar symptoms. The prevalence is low, even in a region with a relatively heavy disease burden. Clinicians should, however, retain a high level of suspicion in patients with persistent symptoms.
\end{abstract}

\section{Hosted file}

OPSCC PTA Submitted.pdf available at https://authorea.com/users/407812/articles/518020-theprevalence-of-oropharyngeal-squamous-cell-carcinoma-in-patients-admitted-with-symptomsof-peritonsillar-abscess-or-cellulitis-a-retrospective-multicentre-study

\section{Hosted file}

OPSCC PTA Table1.pdf available at https://authorea.com/users/407812/articles/518020-the- 
prevalence-of-oropharyngeal-squamous-cell-carcinoma-in-patients-admitted-with-symptomsof-peritonsillar-abscess-or-cellulitis-a-retrospective-multicentre-study

\section{Hosted file}

OPSCC PTA Table2.pdf available at https://authorea.com/users/407812/articles/518020-theprevalence-of-oropharyngeal-squamous-cell-carcinoma-in-patients-admitted-with-symptomsof-peritonsillar-abscess-or-cellulitis-a-retrospective-multicentre-study

\section{Hosted file}

OPSCC PTA Table3.pdf available at https://authorea.com/users/407812/articles/518020-theprevalence-of-oropharyngeal-squamous-cell-carcinoma-in-patients-admitted-with-symptomsof-peritonsillar-abscess-or-cellulitis-a-retrospective-multicentre-study 